\title{
Making Intellectual Property a Common Good to Combat Global Pandemics and the COVID-19 Technology Access Pool (C-TAP): Responding to the Challenges Exerted by Big Pharma and Some High-Income Countries
}

\author{
A.A.C.J. Adikari \\ University of the Visual and Performing Arts, Sri Lanka \\ Sanath Sameera Wijesinghe \\ Queensland University of Technology, Australia / Open University, Sri Lanka
}

\begin{abstract}
The COVID-19 outbreak has created a global race for research into a vaccine, diagnostic and therapeutic among research institutes, governments, and bigtech pharmaceutical companies (Big Pharma). In this context, intellectual property rights (IPRs) play a prominent role in incentivizing COVID-19 vaccines. Simultaneously, IPRs, particularly the patent rights of Big Pharma, create restrictions on fair access to affordable COVID-19 vaccines. Besides, economically powerful high-income countries have purchased and reserved a large amount of COVID-19 vaccines while low and middle-income countries (LMICs) have been struggling to obtain sufficient vaccine doses. These factors have contributed to increasing the gap of access to affordable COVID-19 vaccines between high-income countries and LMICs. Having foreseen the likely effect of LMICs being discriminated against in the global COVID-19 vaccine production and distribution, the global community has already made some efforts to revisit the normative aspects of IPRs by making intellectual property a common good to achieve global health during the pandemic. For example, the World Health Organization (WHO) has launched the COVID-19 Technology Access Pool (C-TAP), considering the proposal made by Costa Rica. The C-
\end{abstract}

Corresponding Author:

A.A.C.J. Adikari, University of the Visual and Performing Arts, Sri Lanka; Email: aachaminya@yahoo.com 
TAP intended to ensure technology transfer, disclosure of research, flexible licensing and open innovations. However, Big Pharma and some high-income countries have criticised and directly interfered in the effective functioning of $C$ TAP. Therefore, there remains a question as to whether the C-TAP approach would only be idealistic or realistic in the global governance of IPRs and public health. Accordingly, this paper critically analyses the prospects that C-TAP would offer LMICs to overcome IPRs-related barriers and resource constraints in accessing the COVID-19 vaccine and reflect on how to tackle Big Pharma and some high-income countries' influences on the effective functioning of $C$ TAP.

\section{Keywords:}

Access to medicine, Big Pharma, COVID-19 vaccine, C-TAP, IP as a common good

\section{Introduction}

The main objective of this paper is to analyse how the global community and international law and policy can contribute to the effective functioning of the COVID-19 Technology Access Pool (C-TAP) to ensure access to affordable COVID-19 vaccines worldwide. In doing so, this paper pays particular attention to how big tech pharmaceutical companies (Big Pharma) ${ }^{1}$ and their supporting high-income countries have responded to C-TAP and the extent to which they have influenced the functioning of C-TAP. This paper further evaluates the common critique on intellectual property (IP) incompatibility of C-TAP through the lens of considering IP as a common good to facilitate health during global pandemic situations. Having analysed the possible barriers that hinder the effective functioning of C-TAP, this paper makes suggestions on how to overcome such barriers. In general, this paper emphasises the importance of a multi-sectoral approach - participation of diverse policy actors in supporting and enabling global health proposals - to respond to global health concerns.

The global race among research institutes, governments and Big Pharma to find a cure for Corona Virus diseases has almost been accomplished with the finding

\footnotetext{
${ }^{1}$ Big Pharma is a commonly used term to indicate multinational pharmaceutical companies. The Merriam-Webster Dictionary defines Big Pharma as 'large pharmaceutical companies considered especially as a politically influential group'.
} 
of COVID-19 vaccines by some pharmaceutical companies. ${ }^{2}$ Particularly, intellectual property rights (IPRs) have played a prominent role in incentivising and accelerating the global race for finding the COVID-19 vaccine. At the same time, IPRs have created significant challenges on the issuance of compulsory licenses, open access for research and innovation, and ultimately the assurance of equal access to affordable COVID-19 vaccine (Chiriboga et al., 2020). In this context, the global health community has faced two challenges: first, to accelerate the global search for safe and effective COVID-19 vaccines and second, to ensure fair access to affordable COVID-19 vaccines. ${ }^{3}$ Considering these challenges, the World Health Organization (WHO) has launched the CTAP to create a voluntary patent pool relating to all medicines, technology sharing and furthering research and development in advancing a COVID-19 vaccine, particularly to mitigate potential IPR-based challenges in finding a COVID-19 vaccine and its fair distribution (Anon 2020a).

Even though the C-TAP seemed to be a pragmatic global solution to ensure access to affordable COVID-19 vaccines worldwide, the global policy actors seem to have diverse opinions on C-TAP. A considerable number of WHO members, health advocates, civil society organizations and philanthropical organizations have embraced this proposal. However, Big Pharma publicly criticized C-TAP, and some high- income countries that are home to large pharmaceutical companies raised their objections at WHO and World Trade Organization (WTO) discussions claiming that C-TAP could erode IPRs and thereby slow the progress of the global search for COVID-19 treatment (Anon, 2020c; Newey, 2020). The criticisms of Big Pharma, and more importantly, the objections raised by some high-income countries that represent the interests of Big Pharma have hindered the effective functioning of C-TAP at the global level. The delays in the proper functioning of C-TAP have created barriers in fair access to technology, know-how and IPRs associated with the COVID-19 vaccine, particularly for low and middle-income countries (LMICs). This situation has affected predominantly on LMICs' capacity of producing or importing adequate COVID-19 vaccine doses.

\footnotetext{
${ }^{2}$ According to existing data Oxford-AstraZeneca, Pifzer-BioNtech, Moderna, Sinopharm-Beijing, Gamaleya (Sputnik V), and Sinovac are the most commonly administrated vaccines throughout the world. ("Coronavirus (COVID-19) Vaccinations Statistics and Research," 2021).

${ }^{3}$ Since vaccine plays a prominent role in the global race for COVID-19 treatment, this paper particularly focuses on analysing the matters relating to the COVID-19 vaccine.
} 


\section{Research Problem}

This paper will consider the research problem: how the global community and international law and policy can contribute to the effective functioning of CTAP to ensure access to affordable COVID-19 vaccine worldwide. The terms 'global community' and 'international law and policy' used in this research question have specific meanings and applications in the context of global governance of the COVID-19 pandemic. The term global community used in this question refers to global policy actors such as the WHO, international nongovernmental organizations (INGOs), civil society organizations, and philanthropic organizations, and in specific cases the WTO which play a vital role in the international governance of trade and IP. The term international law and policy used in this question refers to the specific branches of international law, including international health law and IP law, that affect the implementation of C-TAP and access to the COVID-19 vaccine worldwide.

\section{Methodology}

In answering the above research problem, this paper adopted a legal doctrinal analysis consisting of an extensive literature review and a policy-oriented legal approach. The legal doctrinal methodology has been used in this research to systematically analyse the laws and rules governing C-TAP and access to COVID-19 vaccines, to examine the overlaps of these laws and rules, and to make suggestions for future developments (Hutchinson and Duncan, 2012). An extensive review of primary and secondary legal sources on C-TAP, IPRs and access to medicine were used to identify, evaluate, and suggest how the global community and international law and policy can ensure effective functioning CTAP. Simultaneously, this paper employed a policy-oriented approach to analyse how the emerging COVID-19 pandemic-related political and socioeconomic factors influence formulating global health policies and revitalising normative aspects of IPRs (Chen, 2015; McDougal, 1956).

\section{Conceptual Background and Discussion}

This section consists of five subparts, and they provide the contextual background of the discussion of this paper and the suggestions to ensure the effective functioning of C-TAP. Part One discusses the need for global action to combat the COVID-19 pandemic. Part Two analyses the importance of making intellectual property (IP) a common good during a pandemic and Big Pharma's 
arguments against considering IP as a common good. Part Three examines the scope of C-TAP with particular reference to Big Pharma and its supporting governments' critiques. Part Four provides an analysis of the contribution of CTAP from its inception through to today. Part Five makes suggestions to ensure the proper functioning of C-TAP to achieve its objectives in combating the COVID-19 pandemic and establishing C-TAP as a global mechanism to overcome potential IPR-based challenges of access to fair and affordable vaccine and treatment in future global health disasters.

\section{No one is safe until everyone is safe}

The rapid transmission of the COVID-19 virus has caused nearly 163 million cases of infection and 3.3 million deaths as of 14 May 2021 worldwide (Roser et al., 2020). COVID-19 has created an unprecedented and novel threat to the world (Abrams and Szefler, 2020). Chakraborty and Maity have recognised the COVID-19 pandemic as 'the most crucial global health calamity of the century and the greatest challenge that humankind faced since the Second World War'(Chakraborty and Maity, 2020). Considering the gravity and impact of the crisis on every aspect of human existence, the WHO declared the COVID-19 outbreak as a public health emergency of international concern on 30 January 2020 (Harapan et al., 2020). It has also created a considerable challenge before humankind finds a cure to contain the spread of the virus and to ensure everyone's access to affordable COVID-19 vaccine (Bassi and Hwenda, 2020).

The societal and economic impact of the COVID-19 pandemic varies from one country to another based on their economic capacity and resources. Undoubtedly, the low- and middle-income countries (LMICs) face severe public health concerns with this crisis compared to their high-income counterparts (Abrams and Szefler, 2020). In the pre-COVID-19 era, it was estimated that 2 billion people lacked regular access to essential medicine worldwide, particularly in LMICs (Kohler and Mackey, 2020). For example, the cost of the Hepatitis B vaccine-30 US dollars per dose-was too expensive for many LMICs, and thus, they were not able to afford the vaccine (Vanderslott, Dadonaite, and Roser, 2013; Zakir et al., 2019). Arguably, the COVID-19 pandemic would exacerbate the lack of access to essential medicine and could create considerable health disparities between high-income countries and LMICs. $^{4}$ Further, LMICs would likely lag in the global race for the COVID-19

\footnotetext{
${ }^{4}$ COVID-19 vaccines range from 3 US Dollars (AstraZeneca-Oxford) to 37 US Dollars (Moderna).
} 
vaccine as they lack the necessary resources and financial capacity to engage in high-tech research and innovation (Chiriboga et al., 2020).

As of 14 May 2021, 7.79 billion of the global population has received at least one dose of the COVID-19 vaccine ("Coronavirus (COVID-19) Vaccinations Statistics and Research," 2021). Even though the global COVID-19 vaccine administration has been progressing rapidly since December 2020, it has also been predicted that "it could be September 2023 before [the entire world] have enough doses [of vaccine]" (McDonnell et al., 2020). Besides, there is a considerable gap between high-income countries and LMICs in global COVID19 vaccine administration (Rouw et al., 2021). As the statistical analysis of COVAX $^{5}$ and Duke Global Health Innovation Centre demonstrated there is a gap of COVID-19 vaccine purchase between high-income countries and LMICs (McAdams et al., 2020 : ("Vaccine Procurement: Tracking COVID-19 Vaccine Purchase across the Globe," 2021)). According to this analysis, 57\% of the global COVID-19 vaccine doses were purchased by high-income countries that only account for $19 \%$ of global adult population. Conversely, LMICs only purchased $38 \%$ of global COVID-19 vaccine doses while accounting for $81 \%$ of the global adult population ("Coronavirus (COVID-19) Vaccinations - Statistics and Research," 2021). The huge disparity in terms of vaccine purchase could exacerbate health inequalities between high-income countries and LMICs. Hence, the global community is no longer presented with a task to develop a vaccine to cure COVID-19; however, the global community has the challenge to ensure fair access to affordable COVID-19 vaccines worldwide.

There are two factors that are likely to prevent LMICs from accessing COVID19 vaccines. First, these countries lack the resources to purchase vaccines and develop their own vaccine (Forman et al., 2021). Second, IPRs'-related barriers exerted by Big Pharma could restrict these countries from access to affordable COVID-19 vaccines (Ido, 2020; World Health Organization, 2020). The vulnerability of LMICs accessing the COVID-19 vaccine demands global policy actors' attention and encourages them to consider comprehensive policy options for revitalising the scope of IPRs to accommodate public health concerns. In

\footnotetext{
${ }^{5}$ COVAX is an international partnership that aims to support the development, manufacturing and distribution of COVID-19 vaccines, particularly in LMICs. COVAX consists of international non-governmental organizations such as the Coalition for Epidemic Preparedness Innovations (CEPI), Gavi, the Vaccine Alliance, and the World Health Organization.
} 
such a situation, the C-TAP proposal would be an effective global level solution to ensure 'widespread technology transfer' by lessening the IPRs-related barriers to access COVID-19 vaccines and treatment (Wouters et al., 2021).

Nevertheless, the world would only be safe when all affected people are cured and the spread of the virus is permanently contained, including in LMICs. Hence, the COVID-19 pandemic echoes the notion that 'no one is safe until everyone is safe'. Simultaneously, it demands a supra-national and multisectoral solution rather than a country-specific or a region-specific approach in addressing the IPRs-related challenges to access vaccine and treatment in global pandemics. Hence, reiterating the need for global solution, this paper proposes making IP a common good through C-TAP as one of the best approaches to address this concern. The section below examines the importance of considering IP as a common good to respond to the COVID-19 pandemic.

\section{IP as a common good to respond to the COVID-19 pandemic}

Considering IP as a common good would challenge the exclusivity of IPRs' in their duration of protection and IP owners' rights to use and enjoy their rights, excluding all third parties (Carrier, 2004). However, the dire need to combat the COVID-19 pandemic can be considered a justifiable reason to limit IPRs, particularly patents, by treating them as a common good accessible and useable by third parties for the sole purpose of ensuring access to affordable COVID-19 vaccines around the world. In general, intellectual property has grown over time and entered all aspects of human life in modern days (Sunder, 2010). Even though property rights are considered to be served for human values, there remains a question as to whether the property rights associated with IP truly serve human values or create some barriers and inequalities in access to technology, innovation and knowledge, and realisation of human capabilities (Sunder, 2006). IPRs are largely governed by the Agreement of Trade-Related Aspects on Intellectual Property (TRIPS), which sets the minimum standards for IP protection at the international level (Dinwoodie and Dreyfuss, 2012). The TRIPS Agreement recognises diverse IPRs such as copyrights, trademarks, patents, geographical indications, industrial designs, layout designs, protection for undisclosed information, trade secrets, and control of anti-competitive practises in contractual licenses. More importantly, the TRIPS Agreement outlines the scope of each IPR, ensuring that owners get exclusive protection over their rights for a limited period, however, subject to the exceptions such as 
fair use and achieving public interest and public health goals (Garrison, 2006; Guan, 2016a).

Patent rights have gained considerable attention among Big Pharma and global health actors in the race for COVID-19 vaccines and treatment. Particularly, patent rights propounded on economic ideology and incentive theory could become a major impediment in ensuring equitable access to patented pharmaceuticals (Meiners and Staaf, 1990; Zlinkoff, 1943). The rationale behind granting a time-barred monopoly for the inventor or the manufacturer of the patented product is to compensate his investment in developing such a product and incentivise the same, among other factors (Dam, 1994; Shiffrin, 2009). However, the general conception of patent monopoly backed by the incentive theory could create barriers in access to affordable vaccine in a global pandemic (Kohler and Mackey, 2020). The patent rights obtained by Big Pharma on the COVID-19 vaccine could create different barriers to LMICs access to the vaccine. In distributing the COVID-19 vaccine, Big Pharma could be favourable to high-income countries that often represent Big Pharma's interest in global economic and health forums such as the WHO, TRIPS and WTO councils (Nhamo et al., 2021). For example, AstraZeneca had announced that they offer priority in providing the vaccine for both the USA and the UK in mid of 2020 (Roope et al., 2020). Further, in February 2020, the USA has entered into an investment agreement with Sanofi ${ }^{6}$ to secure preferential and priority access to the future vaccine (Paton, Griffin, and Koons, 2020; Woods et al., 2020). It seems Big Pharma facilitates 'my country first' approach, which is commonly known as vaccine nationalisation (Abbas, 2020a; Phelan et al., 2020). This situation could be unfavourable and perhaps jeopardise LMICs that face severe health consequences with the rapid progression of COVID-19, and at the same time, that lack financial resources to invest in the developing and purchasing COVID-19 vaccines.

The behaviour of Big Pharma and some high-income countries have revealed that patent monopoly and vaccine nationalization could be a deadly combination on the ethical framework of global vaccine allocation and fair distribution of vaccines in the COVID-19 pandemic. To have an ethical framework for global vaccine allocation and distribution, the global community could consider benefiting people by limiting the harm which could be created by patent monopoly and vaccine nationalisation, and prioritizing the needs of

\footnotetext{
${ }^{6}$ Sanofi is a French multinational pharmaceutical company headquartered in Paris, France, as of 2013, the world's fifth largest by prescription sales.
} 
marginalized countries, in this case, LMICs. Considering IPRs as a common good rather than exclusive private property to accommodate more significant societal interests such as public health and human values (Sunder, 2012) would be one way to address the adverse impacts of patent monopoly and vaccine nationalisation on LMICs, particularly in the time of the COVID-19 pandemic.

\section{Patent Monopoly Vs Access to Medicine}

This section provides a theoretical account of patent versus access to medicine debate exploring the involvement and response of Big Pharma. The complex relationship between IPRs and public health is a significant concern in patents and access to medicine debate. As Sam Halabi commented, "the exclusive control given to pharmaceutical patent holders, ... stands at odds with access to affordable medicines' (Halabi, 2014). Nevertheless, it is argued that patent monopolies facilitate profits, new and improved medicines and drive knowledge-based economies. The monopoly granted to a patentee in the current context is justified through factors such as the high cost of research and innovation (Sellin, 2015). Even though the rationale behind patent monopoly is to incentivise innovation, the practice of patent holders-pharmaceutical industry - revealed that patent monopoly is 'gaming the system' by using IPRs to evergreen patents (having rights indefinitely) and profiteer off public health crises (Hassan, 2020). The patent protection granted to a medicine, vaccine or a pharmaceutical product is a dominant factor in bargaining between the patentee and the public (Khachigian, 2020). Even though innovation for treating and preventing acute diseases could assist millions of vulnerable and sick people, access to essential and life-saving diagnostics and therapeutics for many chronic conditions are limited due to a gaming system by patent holders in the pharmaceutical industry.

As a positive response to this issue, the Doha Declaration on TRIPS and Public Health (Doha Declaration) was introduced in 2001 to allow a flexible reading of TRIPS to accommodate 'access to affordable, essential drugs in the developing countries' (Ahmadiani and Nikfar, 2016). Further, it intended to reaffirm the TRIPS members' rights to regulate public health concerns (Abbas and Riaz, 2013; Abbott, 2002). The post-Doha Declaration era provides a contextual basis for realising how Big Pharma and proxy governments interfered and made it difficult for countries, in particular the LMICs, to effectively utilise Doha proposals to promote access to medicine at national level (Novella, 2010; Williams, 2015). They created different obstacles on the TRIPS members' 
efforts to use Doha flexibilities to issue compulsory licenses (CLs) on essential medicine. As discussed in the table below, the most popular tactic was to create hostile situations and impose retaliatory measures against the TRIPS' members' efforts to issue compulsory licenses (Beck et al., 2019; Ford et al., 2007; Wibulpolprasert et al., 2011).

Table 1: Examples for Industry and Lobbying Country Oppositions on the Issuance of Compulsory Licenses

\begin{tabular}{|c|c|c|c|}
\hline Country & Initiative & $\begin{array}{l}\text { Opposed } \\
\text { industry } \\
\text { actor/country }\end{array}$ & $\begin{array}{l}\text { Nature of the hostile } \\
\text { situation or retaliatory } \\
\text { measure }\end{array}$ \\
\hline $\begin{array}{l}\text { Brazil } \\
(2005- \\
2007)\end{array}$ & $\begin{array}{l}\text { The decision to } \\
\text { issue a CL for } \\
\text { antiretroviral } \\
\text { (AVR) drugs }\end{array}$ & $\begin{array}{l}\text { Abbott } \\
\text { Laboratories } \\
\text { United States of } \\
\text { America }\end{array}$ & $\begin{array}{l}\text { Demanded the Brazilian } \\
\text { government to restrict the CL } \\
\text { and moratorium on future } \\
\text { price negotiations until } 2011 \text {. }\end{array}$ \\
\hline $\begin{array}{l}\text { Thailand } \\
\text { (2006 - } \\
\text { 2008) }\end{array}$ & $\begin{array}{l}\text { The decision to } \\
\text { import a } \\
\text { generic version } \\
\text { of ARV drugs } \\
\text { from India } \\
\text { under a CL. } \\
\text { - similar } \\
\text { license to } \\
\text { import ARV } \\
\text { drugs. } \\
\text { - four } \\
\text { additional } \\
\text { licenses to } \\
\text { import cancer } \\
\text { drugs. }\end{array}$ & $\begin{array}{l}\text { United States of } \\
\text { America }\end{array}$ & $\begin{array}{l}\text { Decided to withdraw its } \\
\text { applications for marketing } \\
\text { approval on seven new drugs, } \\
\text { condemning Thailand's } \\
\text { decision to issue CL on its } \\
\text { products. } \\
\text { The Office of the United } \\
\text { States Trade Representative } \\
\text { (USTR) subsequently } \\
\text { removed the Generalised } \\
\text { System of Preference (GSP) } \\
\text { on three products exported by } \\
\text { Thailand. } \\
\text { A letter issued by the } \\
\text { European Trade } \\
\text { Commissioner criticised } \\
\text { Thailand's decision to issue } \\
\text { CL, stating that 'such } \\
\text { approaches could lead to } \\
\text { Thailand isolation from the } \\
\text { global biotechnology } \\
\text { investment community'. }\end{array}$ \\
\hline $\begin{array}{l}\text { India } \\
(2012- \\
2015)\end{array}$ & $\begin{array}{l}\text { The decision to } \\
\text { issue CL for a } \\
\text { cancer drug. }\end{array}$ & $\begin{array}{l}\text { United States of } \\
\text { America }\end{array}$ & $\begin{array}{l}\text { USTR named India on the } \\
\text { 'Priority Watch List', and US } \\
\text { International Trade } \\
\text { Commission (USITC) } \\
\text { investigated India's trade and }\end{array}$ \\
\hline
\end{tabular}




\begin{tabular}{|c|c|c|c|}
\hline Country & Initiative & $\begin{array}{l}\text { Opposed } \\
\text { industry } \\
\text { actor/country } \\
\end{array}$ & $\begin{array}{l}\text { Nature of the hostile } \\
\text { situation or retaliatory } \\
\text { measure }\end{array}$ \\
\hline & & & investment policies. \\
\hline $\begin{array}{l}\text { Colombia } \\
(2016)\end{array}$ & $\begin{array}{l}\text { The decision to } \\
\text { issue a CL on } \\
\text { leukaemia drug } \\
\text { listed in the } \\
\text { WHO's } \\
\text { Essential } \\
\text { Medicines List. }\end{array}$ & $\begin{array}{l}\text { Novartis } \\
\text { Colombia \& } \\
\text { Novartis } \\
\text { International } \\
\text { A.G. } \\
\text { Swiss } \\
\text { Confederation } \\
\text { Colombian } \\
\text { Embassy in the } \\
\text { United States }\end{array}$ & $\begin{array}{l}\text { The Colombian Ministry of } \\
\text { Health received different } \\
\text { communications that } \\
\text { contained the: } \\
\text { - allegations on factual } \\
\text { inaccuracies and distortion of } \\
\text { international trade and IP } \\
\text { obligations; } \\
\text { - threats of dispute settlement } \\
\text { claims; } \\
\text { - threats to suspend the } \\
\text { promised US funding for the } \\
\text { Colombian peace process. }\end{array}$ \\
\hline
\end{tabular}

As evidenced, Big Pharma and highly industrialised countries such as the USA, EU and Switzerland created hostile situations and retaliatory actions against other countries' efforts to issue compulsory licenses. Hence, the examples depicted in the above table witness to the power of Big Pharma and some of the high-income countries, in posing obstacles on the use of internationally agreed norms for access to medicine by the LMICs to achieve their public health goals (Dutfield, 2020). This observation leads us to consider the bigger picture of the capacity and the lobbying power of Big Pharma to suppress global efforts to promote public health. Given Big Pharma and proxy governments resisted the Doha Declaration, one can reasonably imagine how they would respond to a WHO level initiative such as C-TAP that is less binding when compared to the Doha Declaration.

Even today, Big Pharma continues to use their devious tactics, threats and retaliation to lock up the knowledge commons by extending control over lifesaving drugs using patent rights as a tool (Gotzsche 2019). Further, there are some instances in which the pharmaceutical companies protest against the approval and production of generics (Stiglitz, Jayadev, \& Prabhala, 2020). Further, there may be some risks of falsified and substandard medicines, risk of power and influence of pharmaceutical companies and potential system bias, if the process of development of a COVID-19 treatment is left entirely to pharmaceutical companies. Hence, the process should be regulated to some extent and over-sighted by the global health actors, particularly the WHO. 
In addition, there are several reasons IPRs should be considered as a common good in responding to the COVID-19 crisis. First, the territorial nature of IPRs could be a significant impediment in furthering IP as a common good in this global pandemic (Rotstein, 2011). Some countries, such as Canada, Chile and Israel, have already adopted pre-emptive measures that facilitate the effective use of compulsory licenses on prospective COVID-19 treatment (Madar et al., 2020). However, country-specific considerations would not create equal opportunities for all countries, in particular the marginalised LMICs, to access affordable COVID-19 treatment. Therefore, it is essential to consider IPRs as a common good at a global level in advancing COVID-19 treatments and the issuance of compulsory licenses for such treatments. Otherwise, the invented vaccine or COVID-19 treatments will only be an asset for Big Pharma or a particular country with strong IPRs protection. Second, the Doha Provisions for compulsory licensing were rarely applied by TRIPS' members due to their highly technical and time-consuming nature (Bhattacharya 2012; Harris, 2011). In respect of COVID-19 treatment, there should be a useful and prompt mechanism to conclude compulsory licenses between patent holders and generic drug companies. In this context, considering IPRs as a common good through the creation of common IPRs and a technology pool would be a pragmatic solution to remove the IP-based regulatory barriers to research and access COVID-19 treatment.

\section{Patent pooling and C-TAP}

The concept of patent pooling can perhaps be considered as an advanced version that has emerged from the compulsory licensing for access to essential medicine. Patent pooling is an agreement that enables two or more patent holders to license one or more of their patents as a package by enabling the third party to pay associated royalties (Verbeure et al., 2006). As demonstrated in the figure below, in the presence of a patent pooling system, the third parties could quickly obtain licenses from the centralised pool without contacting each patent holder, and with less interaction cost (Luca, 2015). 


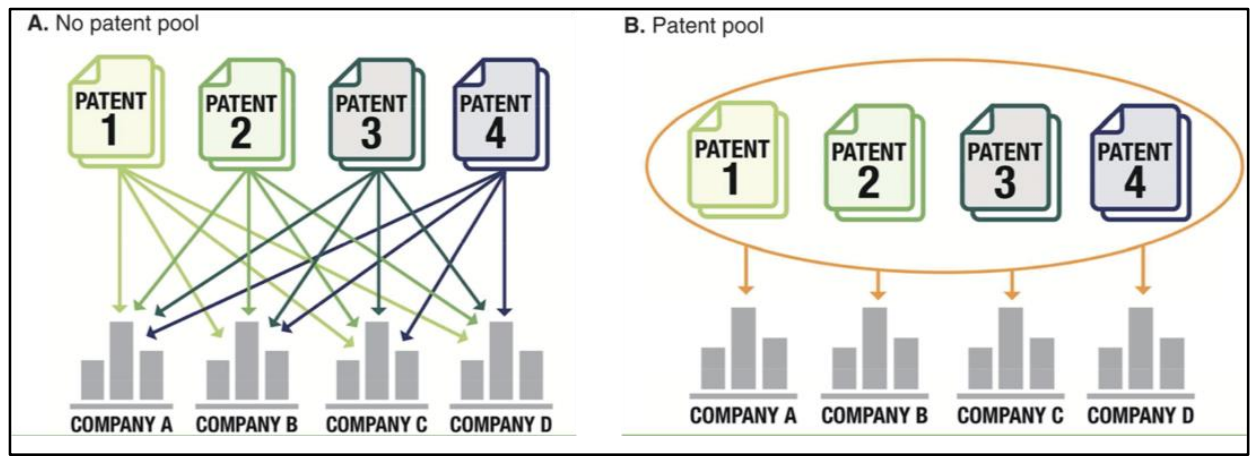

Figure 1: A comparative illustration of the different licenses needed in the absence and presence of patent pooling.

Put in other words, patent pooling encompasses a bundle of benefits such as elimination of stacking licenses, reduction of licensing transaction costs, expedition of the exchange of technical knowledge and information, and discouragement of patent litigation. Given that patent pools require voluntary participation of various patent holders, its success would depend on the voluntariness of patent holders. However, patent pooling has been an innovative solution to remove the stacking of multiple patents and multiple patent holders and to enhance the willingness of technology information sharing by patent holders (Verbeure et al., 2006).

The Medicines Patent Pool (MPP) was the first global level public health patent pool established in 2010 with the mandate of improving 'access to antiretroviral treatment (HIV/AIDS drugs) in the LMICs' (Burrone et al., 2019; Cox, 2012; Ulrich, 2015). Several pharmaceutical companies signed licensing agreements with the MPP by extending their voluntary support (Abbas, 2020b; FM't Hoen, 2016). Subsequently, the MPP's mandate was expanded to include hepatitis $C$ and tuberculosis treatment, the WHO Essential Medicines List, and most recently the COVID-19 medicines and diagnostics (Abbas, 2020b; Moore, 2015). Even though the MPP served as an influential global initiative for patent pooling, its scope was somewhat limited as it is confined to patent rights and limited reach of the LMICs. Accordingly, the C-TAP was launched considering Costa Rica's proposal as an advance global IPR and technology pool to respond to the COVID-19 pandemic effectively. 


\section{Costa Rica's proposal and WHO's involvement in launching of C-TAP:}

In a letter dated March 23, 2020, the President of Costa Rica, Carlos Alvarado, requested the WHO to undertake an effort 'to pool rights and technologies that are useful for the detection, prevention, control and treatment of the COVID-19 pandemic' (Love, 2020). In general, the proposal was aimed at accelerating access to research outcomes, intellectual property and shared data through a collaborative global effort (Abbas, 2020b). More importantly, the proposal encapsulated the ideologies of a global corporation and voluntary participation to promote global nonexclusive voluntary licensing for COVID-19 treatment (Baker, 2020). According to the President, Costa Rica's proposal was a solidarity call for action to all stakeholders, such as WHO members, academia, companies, research institutions and cooperation agencies, to coordinate joint research and development of a vaccine for COVID-19 (WHO and Costa Rica preview technology pooling initiative to ensure access to COVID-19 health products for all, 2020). Hence, Costa Rica's proposal can be considered as a wake-up call for global solidarity to address the regulatory barriers, in particular the barriers associated with IPRs, in responding to the COVID-19 pandemic.

Another significant aspect of this proposal was that it emphasised the need for broadening the scope of technology and IP pool from the traditional focus of patent rights to the broadest possible IPRs needed to accelerate the global search for COVID-19 treatments and their fair distribution (Baker, 2020). As cited in the objectives of Costa Rica's proposal:

This pool, which will involve voluntary assignments, should include existing and future rights in patented inventions and designs, as well as rights in regulatory test data, know-how, cell lines, copyrights and blueprints for manufacturing diagnostic tests, devices, drugs, or vaccines. It should provide for free access or licensing on reasonable and affordable terms, in every member country (Carlos Alvarado Quesada, Presidente de la República, Costa Rica, and Daniel Salas Peraza, Ministro de Salud, Costa Rica, 2020).

Therefore, Costa Rica's proposal seems to be more comprehensive than the MPP as the proposal provides 'broader focus of IPRs' and emphasises the need for a 'global approach' (Abbas, 2020b). Based on Costa Rica's open letter, the WHO launched C-TAP on May 29, 2020. Through this initiative, the WHO intended to provide an encompassing strategy for scientific knowledge, technology, data and intellectual property shared equitably among all research 
of the globe (Love, 2020). The C-TAP has the following five key objectives (Anon, 2020a).

1. Public disclosure of gene sequences and data.

2. Transparency around the publication of all clinical trial results.

3. The collaboration of governments and other funders encouraged to include clauses in funding agreements with pharmaceutical companies and other innovators about equitable distribution, affordability, and the publication of trial data.

4. Licensing of any potential treatment, diagnostic, vaccine, or other health technology to the MPP.

5. Development of life-saving medicines for LMICs and promotion of open innovation models and technology transfer that increase local manufacturing and supply capacity through joining the Open COVID Pledge and the Technology Access Partnership (TAP).

As seen, all five objectives of the C-TAP associate with multiple forms of IPRs that may be involved in the process of developing and distributing COVID-19 treatment. Accordingly, this global initiative lays a foundation to consider different IPRs such as patents (Guderian, Bican, Riar, \& Chattopadhyay, 2021), copyrights (Abeysekara, 2011 and 2012), know-how, and software rights (Kumar, Gupta, \& Srivastava, 2020) to be considered as a common good for the sole purpose of accelerating global efforts to combat the COVID-19 pandemic. These objectives do not necessarily mean that the C-TAP would remove entire IPRs from its holders; instead, they require right holders to respect and accommodate the public health exceptions associated with IPRs concerning the global pandemic situation (Baldini and Bonadio, 2020). Hence, it is irrational to argue that C-TAP would eliminate protected IPRs of Big Pharma, and create a permanent negative and unclear precedent in the global research and development landscape (Millar, 2020).

The C-TAP has gained considerable global attention and 37 WHO members, including Sri Lanka, have informed the WHO that they join the 'solidarity call to action' to make it a reality and ensure its effective implementation (Anon, 2020c). At the same time, Big Pharma and proxy governments have entered into a war against C-TAP, claiming this initiative deprives their IPRs and vested interests while creating a negative precedent in the global IP landscape. The section below analyses Big Pharma and proxy governments' responses on CTAP. 


\section{Big Pharma and its proxy governments' response on C-TAP:}

There has been a considerable resistance from pharmaceutical giants such as AstraZeneca, GlaxoSmithKline, Pfizer, and Johnson \& Johnson since the discussion on COVID-19 patent pooling was started (Newey, 2020). Albert Bourla, the Chief Executive of Pfizer pharmaceutical company, has criticised CTAP, stating that:

I think it is nonsense, and at this point, it is also dangerous. There is an enormous effort right now happening to find a solution. The risks we are taking [represent] billions of dollars and the chances of developing something are still not very good (Newey, 2020).

This argument reflects the Big Pharma's position, which always focuses on IP as a motivation for innovations and advanced drug marketing (Grabowski, 2002; Hartmann, 2017). Even though many countries supported C-TAP, the USA has rejected 'any involvement' to the process (Silverman, 2020). It is not surprising that Big Pharma and the USA continue to criticise and disapprove CTAP, as they have a known history of challenging every pragmatic change introduced to counterbalance IP monopoly, in particular, patent rights over pharmaceutical drugs. Big Pharma's response to early patents pools provides similar examples of resistance. When UNITAID established the MPP in 2009 (New, 2009), some pharmaceutical companies explicitly mentioned that 'they could better accelerate access to medicine themselves rather [than] sign up to the pool' (Jack, 2010). Big Pharma's response to C-TAP seemed to be more aggressive and agitated when compared to their response on MPP. Big Pharma tends to highlight IP as a big issue to challenge and discredit the C-TAP proposal. For instance, as the Chief Executive of AstraZeneca pharmaceutical company stated:

"I think IP is a fundamental part of our industry and if you do not protect $I P$, then essentially there is no incentive for anybody to innovate" (Newey 2020).

Further, the International Federation of Pharmaceutical Manufacturers Association (IFPMA), the executives of top pharmaceutical companies, have questioned the C-TAP, criticising its aim for a voluntary IP pooling (Anon, 2020b). Moreover, the Coalition for Epidemic Preparedness Innovations (CEPI), one of the leading vaccine funding groups, has opposed Costa Rica's proposal, stating that 'it is not effective and not necessary' (Story, 2020). For the success of C-TAP, it is essential to obtain support from major 
pharmaceutical companies and highly industrialised countries in which such companies are housed. Such support would dispel the uncertainties of the effectiveness of C-TAP and contribute to rejecting the IP incompatibility argument often leveled against the C-TAP proposal.

\section{Functioning of C-TAP and the journey so far}

It has been nearly ten months since WHO launched C-TAP 'calling the global community to share knowledge, IPRs and data necessary for [finding and distributing] COVID-19[vaccine and treatment]'(Anon, 2020a). Even though this global initiative has received considerable global attention ever since, little global action has been taken to realize its objectives (Hoen, 2021). Seemingly, Big Pharma and some high-income countries have played a vital role in the process of obstructing the functioning of C-TAP (Anon, 2021). At the same time, WHO and WTO member states and civil society organizations such as Oxfam that represent People's Vaccine Alliance and Health Action International have directly been involved in encouraging WHO to take concrete actions to realize the objectives of C-TAP (Hoen, 2021). This section assesses the controversial journey of C-TAP so far, referring to its ups and downs, and the future prospects.

A considerable number of WHO member countries, mainly the countries in LMICs' cluster, have taken substantial efforts to make C-TAP a reality rather than a proposal. Ethiopia submitted a draft resolution to WHO in December 2020, highlighting the challenges faced by developing nations in establishing robust local production facilities for vaccines, treatments and other health technologies (Balasubramanium, 2021). Expanding this proposal, China, Eswatini, Ethiopia, Ghana, Kenya, Namibia, Rwanda, South Africa, Sudan, Togo and Zimbabwe have submitted the resolution Strengthen Local Production of Medicines and other Health Technologies to Improve Access to the Executive Board of WHO in January 2021. ${ }^{7}$ Even though this resolution recalls the global commitments towards enabling C-TAP, it has not been concluded yet due to the WHO members' diverse opinions on the language referring to TRIPS health flexibilities and transparency of the C-TAP proposal (Balasubramanium, 2021). A similar incident happened in the TRIPS Council when considering India and South Africa's proposal to temporarily waive

\footnotetext{
${ }^{7}$ See, PP20 bis of the Resolution Strengthen Local Production of Medicines and other Health Technologies to Improve Access, EB148/CONF./9, World Health Organization, $148^{\text {th }}$ Session of the Executive Board, (21 January 2021).
} 
TRIPS provisions on copyrights and related rights, industrial designs, patent and undisclosed information to 'prevention, containment or treatment of COVID19'(Usher, 2020). ${ }^{8}$ High-income countries such as Switzerland, European Union and the UK opposed this proposal claiming that a 'well-functioning IPR system would be a solution rather than an obstacle to developing a safe and effective vaccine for COVID-19 (Balasubramanium, 2020; Reuters Staff, 2021). These oppositions have made India and South Africa's proposal of temporarily waving TRIPS provisions inconclusive at the TRIPS Council (Mercurio, 2021).

The resolution submitted to the WHO and the proposal presented at the TRIPS Council can be considered substantial efforts taken by countries to recognise the underline premise of C-TAP, which encourages considering IP as a common good to ensure fair access to affordable COVID-19 vaccines worldwide. However, the same considerations of IPRs have been the trigger that creates disagreements between high-income countries where most pharmaceutical industries are housed, and LMICs are keen to obtain fair access to affordable COVID-19 vaccines. Thus, the lack of political support and resistance of some high-income countries prone to represent the interests of Big Pharma have been two key factors that influence the effective functioning of C-TAP at the global level. Further, less faith in C-TAP has evolved due to a lack of clarifications on who provides political leadership for C-TAP and who undertakes the responsibility of ensuring transparency of C-TAP activities.

If C-TAP is supported by many developed nations and functioned efficiently to achieve its major objectives, it could create fair opportunities to distribute the COVID-19 vaccine worldwide. If C-TAP has functioned as intended, it would have expedited manufacturing the COVID-19 vaccine and ensured the transparency of the publishing and disclosing important clinical trials conducted by Big Pharma. Further, if C-TAP has properly functioned through its initiation, it would have contributed to encourage redistribution of resources and finance to ensure that LMICs get the necessary support to overcome resource constraints in manufacturing or buying the COVID-19 vaccine. Moreover, CTAP would have been detrimental to the proper functioning of COVAX, which provides a significant contribution towards financing and distribution of COVID-19 vaccines among LMICs (Anon, 2021; McAdams et al., 2020). However, the journey so far has not been favourable to the proper functioning of

\footnotetext{
${ }^{8}$ Waiver from Certain Provisions of the TRIPS Agreement for the Prevention, Containment and Treatment of COVID-19, IP/C/W/669, World Trade Organization, Council for TRIPS, (02 October 2020).
} 
C-TAP with its full strength. Hence, it is reasonable to argue that C-TAP has been underutilized or perhaps underperformed at the global level in ensuring that LMICs are not left behind in the battle against COVID-19.

\section{The uphill battle: responsibility of the global community to advance C-TAP}

Seemingly, the global community has an uphill battle in establishing C-TAP as a global mechanism to facilitate the transfer of technology, IPR and research data necessary to ensure fair and affordable access to the COVID-19 vaccine. The need to make IP a common good through C-TAP can be considered the recent most example of the lingering conflict between IP and public health since adopting the TRIPS Agreement. Even though the TRIPS flexibilities and Doha Declaration provided practical proposals to harness this conflict, it seems Big Pharma and its supporting countries continue to circumvent such proposals using their might. They have already expressed their disappointment with $\mathrm{C}$ TAP (Newey, 2020). Seemingly, there is a strong likelihood that Big Pharma, and proxy governments would continue to use any tactic to dilute the effective functioning of C-TAP. Hence, it is immature to think that anyone could stop Big Pharma and its supporting countries from undermining pragmatic health proposals such as C-TAP. However, the global community could collectively resist and manage such influences(Ekström et al., 2021). Accordingly, this paper suggests increased stakeholder participation and strong corroboration between the WHO and WTO as significant factors in responding to Big Pharma and its supporting governments' interference in enabling C-TAP.

Global solidarity is considered one of the pillars of global governance for health (Gostin, 2014). There have been different calls for stakeholder participation and global corroboration in respect to the C-TAP initiative. The 'General Assembly of the United Nations Resolution on International Cooperation to Ensure Global Access to Medicines, Vaccines and Medical Equipment to Face COVID-19, 9 and the $73^{\text {rd }}$ World Health Assembly Resolution on "COVID-19 Response""10 were adopted to escalate global commitment for a COVID-19 response (Anon, 2020c). These international commitments invited the global actors including, countries and research development funders, knowledge holders of IPRs or data on existing or novel treatments, researchers, patients and communities, inter-

\footnotetext{
${ }^{9}$ Resolution on International Cooperation to Ensure Global Access to Medicines, Vaccines and Medical Equipment to Face COVID-19, A/RES/74/274, General Assembly, UN Doc. A/74/L.56 (08 April 2020).

${ }^{10}$ COVID-19 Response, A73/CONF./1 Rev.1, World Health Organization, $73^{\text {rd }}$ World Health Assembly, (18 May 2020).
} 
governmental and non-governmental organizations, and all stakeholders to confirm their participation and accountability for the global action towards combating COVID-19, which includes enabling C-TAP.

The tug of war between some high-income countries and LMICs concerning CTAP at the international level provides an example of the fragmentation of international law (Koskenniemi and Leino, 2002; Trachtman, 2011; Young, 2012). At the same time, it emphasizes the importance of integrating health and IP norms and building partnerships among TRIPS Council, WTO, and WHO to respond to global health crises (Drope and Lencucha, 2014). Therefore, it needs greater co-operation between WHO and WTO to minimise the normative and institutional fragmentation of health and IP norms simultaneously in enabling the effective functioning of C-TAP. Given that WTO focuses on trade liberalization, we cannot reasonably expect WTO to facilitate C-TAP as the WHO does. However, WTO could facilitate and encourage the integration of trade norms with health norms, particularly in the ongoing discussions of temporarily waving TRIPS provisions at the TRIPS council (Zarocostas, 2021).In fact, as the paternity rights holder of C-TAP and as the custodian of global health, WHO has a greater responsibility to enable C-TAP's functioning with the support of its member countries. As clearly stated in a letter sent by OXFAM addressing the WHO Director-General, WHO could provide further clarifications of aspects such as the strategy, mandate, political leadership and the mechanism of ensuring transparency of that activities carryout by C-TAP (Hoen, 2021). Further, it is also important that WHO drafts model agreements that C-TAP could use in concluding matters of sharing of rights in the invention, research data, biological resources, knowhow and knowledge transfer.

In addition to these institutional collaborations and the particular involvements of WHO, the following two aspects should be considered in justifying C-TAP in international law and policy, particularly in the context of IPR regulations. First, the normative integration of IP, human rights and public health can be used as a theoretical base for verifying IP as a common good through the C-TAP amid the COVID-19 pandemic. The normative integration of IP and public health emphasises that individual IPRs should be interpreted and understood in a manner sensitive to public health (Guan, 2016b). Accordingly, international developments of IP and public health could be used to defend IP-based challenges on the C-TAP proposal. Second, the cardinal premise of the Sustainable Development Goals 2030 Agenda (SDGs) - 'leave no one behind' can be used to justify the need for global participation to ensure the LMICs are 
not left behind in the global race for COVID-19 vaccines (Buse and Hawkes, 2015; Filho et al., 2019). Further, SDGs Goal 3, which denotes 'health and wellbeing for all', and SDGs Goal 17, which requires 'global participation', can be used to substantiate collaborative actions towards enabling C-TAP ("Sustainable development goals - United Nations," n.d.). These aspects would contribute to verifying IP as a common good in the time of the COVID-19 pandemic, foster stakeholder participation and global corroboration to ensure the smooth functioning of C-TAP, and finally, affirm fair distribution of COVID-19 vaccines among every country without discrimination.

\section{Conclusion}

This paper concludes that the participation of global policy actors, including the partnership among the WHO, WTO and TRIPS Council, are important factors in tackling the influence of Big Pharma and some high-income countries on the effective functioning of C-TAP to ensure that every country gets a fair opportunity to access affordable COVID-19 vaccines. As this paper has investigated the cardinal premise of C-TAP - making IP a common good to respond to the COVID-19 pandemic - it provides a theoretical account of the role of IPRs in a global health crisis. In this vein, this paper emphasizes the importance of making IP a common good to uphold health equity which ultimately every country receives fair opportunities to access affordable medicine, particularly in global health emergencies such as the COVID-19 pandemic. Further, this paper witnesses the power that the multinational corporations have accumulated, particularly Big Pharma, and how these companies and some high-income countries react to undermine the global health proposals utilising the IPRs protected under the TRIPS Agreement. Big Pharma's intervention on C-TAP mirrors how multinational companies interfere with shaping international law and policy, particularly the global health proposals (Freudenberg, 2014). Similarly, there is a tendency that Big Tobacco, Big Alcohol and Big Food use their full might to interfere with the effective implementation of pragmatic global health policies (Damle, 2018; Delobelle, 2019; Reeve and Gostin, 2019). These multinational corporations are economically powerful, politically strong and strategically equipped in subverting any health policy which may affect their trade, profitability and longterm sustainability. Big Pharma's blatant war against C-TAP is a clear demonstration of this long-lasting issue. Hence, the COVID-19 crisis can be considered as a wake-up call for the global health community, and countries to proactively resist and manage pharmaceutical industry tactics and the 
involvements of their supporting high-income countries in undermining the global health proposals. The solidarity action would make the public health community and stakeholders more potent than Big Pharma and some of the high-income countries that lobby for Big Pharma. Such a commitment would ultimately pave the way to ensure effective functioning of C-TAP and access to fair and affordable COVID-19 vaccines worldwide in the current pandemic situation; and lay a strong global-level foundation that could be used to mitigate similar effects in future global health disasters.

\section{Declaration of Conflicting Interests}

The authors declared no potential conflicts of interest with respect to the research, authorship, and publication of this article.

\section{Authors' Contributions}

A.A.C.J Adikari carried out the preliminary literature review and drafted the manuscript. Sanath Sameera Wijesinghe carried out further literature review and contributed to develop the manuscript. Both authors have read and approved the final version of the manuscript and agree with the order of presentation of the authors.

\section{References}

Abbas, Muhammad Zaheer. 2020a. Practical Implications of 'Vaccine Nationalism': A Short-Sighted and Risky Approach in Response to COVID19. Research Paper 124. Geneva, Switzerland: South Centre.

Abbas, Muhammad Zaheer. 2020b. "Treatment of the Novel COVID-19: Why Costa Rica's Proposal for the Creation of a Global Pooling Mechanism Deserves Serious Consideration?" Journal of Law and the Biosciences 7(1). doi: 10.1093/jlb/lsaa049.

Abbas, Muhammad Zaheer, and Shamreeza Riaz. 2013. "Evolution of the Concept of Compulsory Licencing: A Critical Analysis of Key Development before and after TRIPS." Academic Research International 4(2):18.

Abbott, Frederick M. 2002. "The Trips Agreement, Access to Medicines, and the Wto Doha Ministerial Conference." The Journal of World Intellectual Property 5(1):15-52. doi: 10.1111/j.1747-1796.2002.tb00147.x.

Abeysekara, T. B. (2011). The Legality of Copyright and Its Expansion in Times of Yore. Bracton Law Journal, 43, 91-101. 
Abeysekara, T. B. (2012). Historical Evolving of legal Junctures in Copyright which Shaped up the Civilization Process. Journal of Sociology and Social Anthropology, 15(6), 319-325.

Abrams, Elissa M., and Stanley J. Szefler. 2020. "COVID-19 and the Impact of Social Determinants of Health.” The Lancet Respiratory Medicine 0(0). doi: 10.1016/S2213-2600(20)30234-4.

Ahmadiani, Saeed, and Shekoufeh Nikfar. 2016. "Challenges of Access to Medicine and the Responsibility of Pharmaceutical Companies: A Legal Perspective." DARU Journal of Pharmaceutical Sciences 24. doi: 10.1186/s40199-016-0151-z.

Anon. 2020a. "COVID-19 Technology Access Pool." World Health $\begin{array}{lll}\text { Organization. } & \text { Retrieved } & \text { August }\end{array}$ (https://www.who.int/emergencies/diseases/novel-coronavirus-2019/globalresearch-on-novel-coronavirus-2019-ncov/covid-19-technology-accesspool).

Anon. 2020b. Global Biopharma CEO/Top Executives COVID-19 Media Briefing.

Anon. 2020c. "Making the Response to COVID-19 a Public Common Good: Solidarity Call to Action." World Health Organization. Retrieved September 22, 2020 (https://www.who.int/emergencies/diseases/novel-coronavirus2019/global-research-on-novel-coronavirus-2019-ncov/covid-19-technologyaccess-pool/solidarity-call-to-action).

Anon. 2021. "Vaccine Scarcity Is Not Necessary If Drug Companies Share Their Knowledge.” KIT Royal Tropical Institute. Retrieved April 14, 2021 (https://www.kit.nl/vaccine-scarcity-is-not-necessary-if-drug-companiesshare-their-knowledge/).

Baker, Brook K. 2020. "Rationale for Supporting Costa Rica's Proposal for Emergency COVID-19 Technology IP Pool for All Countries" Infojustice. Retrieved September 22, 2020 (http://infojustice.org/archives/42137).

Balasubramanium, Thiru. 2020. "WTO TRIPS Council (October 2020): European Union Dismisses Concerns That IPRs Are a Barrier to COVID-19 Medicines and Technologies." Knowledge Ecology International. Retrieved April 14, 2021 (https://www.keionline.org/34275).

Balasubramanium, Thiru. 2021. "Fissures on Intellectual Property, C-TAP and Transparency Emerge in WHO Local Production Negotiations." Knowledge Ecology International. Retrieved April 14, 2021 (https://www.keionline.org/35873). 
Baldini, Andrea, and Enrico Bonadio. 2020. "Drug Companies Should Drop Their Patents and Collaborate to Fight Coronavirus." The Conversation. Retrieved September 20, 2020 (http://theconversation.com/drug-companiesshould-drop-their-patents-and-collaborate-to-fight-coronavirus-135241).

Bassi, Luca Li, and Lenias Hwenda. 2020. "COVID-19: Time to Plan for Prompt Universal Access to Diagnostics and Treatments." The Lancet Global Health 8(6):e756-57. doi: 10.1016/S2214-109X(20)30137-6.

Beck, Eduard J., Sundhiya Mandalia, Boniface DongmoNguimfack, Eloan Pinheiro, Ellen 't Hoen, Pascale Boulet, John Stover, Aashta Gupta, Sandeep Juneja, Vincent Habiyambere, Peter Ghys, and Cesar Nunez. 2019. "Does the Political Will Exist to Bring Quality-Assured and Affordable Drugs to Low- and Middle-Income Countries?" Global Health Action 12(1):12. doi: 10.1080/16549716.2019.1586317.

Bhattacharya, Alexandra. 2012. "The Use of Paragraph 6 of the Doha Declaration on the TRIPS Agreement and Public Health (2001): A Review of Implementation Experiences in the Developing Countries." Journal of World Investment \& Trade 13:186-209.

Burrone, Esteban, Dzintars Gotham, Andy Gray, Kees de Joncheere, Nicola Magrini, Yehoda M. Martei, Charles Gore, and Marie Paule Kieny. 2019. "Patent Pooling to Increase Access to Essential Medicines." Bulletin of the World Health Organization 97(8):575-77. doi: 10.2471/BLT.18.229179.

Buse, Kent, and Sarah Hawkes. 2015. "Health in the Sustainable Development Goals: Ready for a Paradigm Shift?" Globalization and Health 11:13. doi: 10.1186/s12992-015-0098-8.

Carrier, Michael A. 2004. "Cabining Intellectual Property through a Property Paradigm.” Duke Law Journal 54(1):1-146.

Chakraborty, Indranil, and Prasenjit Maity. 2020. "COVID-19 Outbreak: Migration, Effects on Society, Global Environment and Prevention.” Science of The Total Environment 728:138882. doi: 10.1016/j.scitotenv.2020.138882.

Chen, Lung-chu. 2015. An Introduction to Contemporary International Law : A Policy-Oriented Perspective. 3rd ed. New York: Oxford University Press.

Chiriboga, David, Juan Garay, Paulo Buss, Rocío Sáenz Madrigal, and Laetitia Charmaine Rispel. 2020. "Health Inequity during the COVID-19 Pandemic: A Cry for Ethical Global Leadership." The Lancet 0(0). doi: 10.1016/S01406736(20)31145-4.

Coronavirus (COVID-19) Vaccinations-Statistics and Research. (2021, May 14). Our World in Data. Retrieved May 22, 2021 (https://ourworldindata.org/covid-vaccinations) 
Cox, Krista L. 2012. "The Medicines Patent Pool: Promoting Access and Innovation for Life-Saving Medicines through Voluntary Licenses." Hastings Science \& Technology Law Journal 4(2):291-324.

Dam, Kenneth W. 1994. "The Economic Underpinnings of Patent Law." The Journal of Legal Studies 23(1):247-71. doi: 10.1086/467923.

Damle, S. G. 2018. "Big Tobacco, Big Food, Big Alcohol 'Lifestyle Diseases.", Contemporary Clinical Dentistry 9(3):327-29. doi: 10.4103/ccd.ccd_580_18.

Delobelle, Peter. 2019. "Big Tobacco, Alcohol, and Food and NCDs in LMICs: An Inconvenient Truth and Call to Action." International Journal of Health Policy and Management 8(12):727-31. doi: 10.15171/ijhpm.2019.74.

Dinwoodie, Graeme B., and Rochelle C. Dreyfuss. 2012. A Neofederalist Vision of TRIPS: The Resilience of the International Intellectual Property Regime. USA: Oxford University Press.

Drope, Jeffrey, and Raphael Lencucha. 2014. "Evolving Norms at the Intersection of Health and Trade." Journal of Health Politics, Policy and Law 39(3):591-631. doi: 10.1215/03616878-2682621.

Dutfield, Graham. 2020. That High Design of Purest Gold, A Critical History of the Pharmaceutical Industry, 1880-2020. World Scientific.

Ekström, Anna Mia, Camilla Berggren, Göran Tomson, Lawrence O. Gostin, Peter Friberg, and Ole Petter Ottersen. 2021. "The Battle for COVID-19 Vaccines Highlights the Need for a New Global Governance Mechanism." Nature Medicine 1-2. doi: 10.1038/s41591-021-01288-8.

Filho, W. Leal, S. K. Tripathi, J. B. S. O. D. Andrade Guerra, R. Giné-Garriga, V. Orlovic Lovren, and J. Willats. 2019. "Using the Sustainable Development Goals towards a Better Understanding of Sustainability Challenges." International Journal of Sustainable Development \& World Ecology 26(2):179-90. doi: 10.1080/13504509.2018.1505674.

FM't Hoen, Ellen. 2016. Private Patents and Public Health: Changing Intellectual Property Rules for Access to Medicines. Health Action International.

Ford, Nathan, David Wilson, Gabriela Costa Chaves, Michel Lotrowska, and Kannikar Kijtiwatchakul. 2007. "Sustaining Access to Antiretroviral Therapy in the Less-Developed World: Lessons from Brazil and Thailand." AIDS 21: S21. doi: 10.1097/01.aids.0000279703.78685.a6.

Forman, Rebecca, Soleil Shah, Patrick Jeurissen, Mark Jit, and Elias Mossialos. 2021. "COVID-19 Vaccine Challenges: What Have We Learned so Far and 
What Remains to Be Done?" Health Policy. doi: 10.1016/j.healthpol.2021.03.013.

Freudenberg, Nicholas. 2014. Lethal but Legal: Corporations, Consumption, and Protecting Public Health. Oxford, United States: Oxford University Press, Incorporated.

Garrison, Christoper. 2006. Exceptions to Patent Rights in Developing Countries. Issue Paper. UNCTAD - ICTSD Project on IPRs and Sustainable Development.

Gostin, Lawrence O. 2014. Global Health Law. Harvard University Press.

Gotzsche, Peter. 2019. Deadly Medicines and Organised Crime: How Big Pharma Has Corrupted Healthcare. CRC Press.

Grabowski, Henry. 2002. "Patents, Innovation and Access to New Pharmaceuticals." Journal of International Economic Law 5(4):849-60. doi: 10.1093/jiel/5.4.849.

Guan, Wenwei. 2016a. "IPRs, Public Health, and International Trade: An International Law Perspective on the TRIPS Amendment." Leiden Journal of International Law 29(2):411-40. doi: 10.1017/S092215651600008X.

Guan, Wenwei. 2016b. "IPRs, Public Health, and International Trade: An International Law Perspective on the TRIPS Amendment." Leiden Journal of International Law 29(2):411-40. doi: 10.1017/S092215651600008X.

Guderian, C. C., Bican, P. M., Riar, F. J., \& Chattopadhyay, S. (2021). Innovation management in crisis: Patent analytics as a response to the COVID-19 pandemic. $R \& D$ Management, 51(2), 223-239. https://doi.org/10.1111/radm.12447.

Halabi, Sam F. 2014. "Multipolarity, Intellectual Property, and the Internationalization of Public Health Law." Michigan Journal of International Law; Ann Arbor 35(4):715-71.

Harapan, Harapan, Naoya Itoh, Amanda Yufika, Wira Winardi, Synat Keam, Haypheng Te, Dewi Megawati, Zinatul Hayati, Abram L. Wagner, and Mudatsir Mudatsir. 2020. "Coronavirus Disease 2019 (COVID-19): A Literature Review." Journal of Infection and Public Health 13(5):667-73. doi: 10.1016/j.jiph.2020.03.019.

Harris, Donald. 2011. "TRIPS After Fifteen Years: Success or Failure, as Measured by Compulsory Licensing." Journal of Intellectual Property Law 18:35.

Hartmann, Stephanie. 2017. "When Two International Regimes Collide: An Analysis of the Tobacco Plain Packaging Disputes and Why Overlapping Jurisdiction of the WTO and Investment Tribunals Does Not Result in 
Convergence of Norms." UCLA Journal of International Law and Foreign Affairs 21:204-45.

Hassan, Fatima. 2020. "Politics, Power and Patents: 'Desperate Diseases Require Desperate Measures." Daily Maverick, September 6.

Hoen, Ellen 't. 2021. "The Elephant in the Room at the WHO Executive

Board." Medicines Law \& Policy. Retrieved April 14, 2021 (https://medicineslawandpolicy.org/2021/01/the-elephant-in-the-room-at-thewho-executive-board/).

Hutchinson, Terry, and Nigel Duncan. 2012. "Defining and Describing What

We Do: Doctrinal Legal Research.” Deakin Law Review 17(1):83-120.

Ido, Vitor Henrique Pinto. 2020. Designing Pro-Health Competition Policies in Developing Countries. Research Report. Geneva, Switzerland: South Centre. Jack, Andrew. 2010. "Pharmaceutical Groups Set up Generics Initiative." Financial Times, July 21.

Khachigian, Levon M. 2020. "Pharmaceutical Patents: Reconciling the Human Right to Health with the Incentive to Invent." Drug Discovery Today 25(7):1135-41. doi: 10.1016/j.drudis.2020.04.009.

Kohler, Jillian C., and Tim K. Mackey. 2020. "Why the COVID-19 Pandemic Should Be a Call for Action to Advance Equitable Access to Medicines." BMC Medicine 18(1):193. doi: 10.1186/s12916-020-01661-3.

Koskenniemi, Martti, and Päivi Leino. 2002. "Fragmentation of International Law? Postmodern Anxieties." Leiden Journal of International Law 15(3):553-79. doi: 10.1017/S0922156502000262.

Kumar, A., Gupta, P. K., \& Srivastava, A. (2020). A review of modern technologies for tackling COVID-19 pandemic. Diabetes \& Metabolic Syndrome: Clinical Research \& Reviews, 14(4), 569-573. https://doi.org/10.1016/j.dsx.2020.05.008.

Love, James. 2020. "President and Minister of Health of Costa Rica Ask WHO to Create Global Pool for Rights in COVID-19 Related Technologies." Knowledge Ecology International. Retrieved September 22, 2020 (https://www.keionline.org/32556).

Luca, Carmela De. 2015. "Medicine Patent Pool - Pharma Philanthropy or PR?" Expert Opinion on Therapeutic Patents 25(11):1223-27. doi: 10.1517/13543776.2015.1075004.

Madar, Suzy, Kim O’Conell, Scott Bouvier, Matt Swinn, and Sarah-Jane Frydman. 2020. "Patent Rights during COVID-19 - Can the Government Step In?" Kings \& Wood Mallesons. Retrieved September 25, 2020 (https://www.kwm.com/en/au/knowledge/insights/patent-rights-duringcovid-19-can-the-government-step-in-20200403). 
McAdams, David, Kaci Kennedy McDade, Osondu Ogbuoji, Matthew Johnson, Siddharth Dixit, and Gavin Yamey. 2020. "Incentivising Wealthy Nations to Participate in the COVID-19 Vaccine Global Access Facility (COVAX): A Game Theory Perspective." BMJ Global Health 5(11):e003627. doi: 10.1136/bmjgh-2020-003627.

McDonnell, Anthony, Robert Van Exan, Steve Lloyd, Laura Subramanian, Kalipso Chalkidou, Adrian La Porta, Jiabin Li, Eddine Maiza, and David Reader. 2020. "COVID-19 Vaccine Predictions: Using Mathematical Modelling and Expert Opinions to Estimate Timelines and Probabilities of Success of COVID-19 Vaccines." Washington (DC): Center for Global Development. URL: Https://Www. Cgdev. Org/Sites/Default/Files/COVID19-Vaccine-Predictions-Full. Pdf (Last Accessed: 24.10. 2020).

McDougal, Myres S. 1956. "Law as a Process of Decision: A Policy-Oriented Approach to Legal Study." Natural Law Forum 1:53-72.

Meiners, Roger E., and Robert J. Staaf. 1990. "Patents, Copyrights, and Trademarks: Property or Monopoly." Harvard Journal of Law \& Public Policy 13(3):911-48.

Mercurio, Bryan. 2021. "WTO Waiver from Intellectual Property Protection for COVID-19 Vaccines and Treatments: A Critical Review." Verginia Journal of International Law (Forthcoming). doi: 10.2139/ssrn.3789820.

Millar, Abi. 2020. "Intellectual Property in the Time of Covid-19." Pharma Technology Focus, July.

Moore, Katherine. 2015. "The Medicines Patent Pool Expands Mandate to Hepatitis C and Tuberculosis Treatment." Medicines Patent Pool. Retrieved September 25, 2020 (https://medicinespatentpool.org/news-publicationspost/the-medicines-patent-pool-expands-mandate-to-hepatitis-c-andtuberculosis-treatment/).

New, William. 2009. "UNITAID Drug Patent Pool Implementation Hinges On Board." Intellectual Property Watch. Retrieved September 21, 2020 (https://www.ip-watch.org/2009/12/11/unitaid-drug-patent-poolimplementation-hinges-on-board/).

Newey, S. (2020, May 29). WHO patent pool for potential Covid-19 products is 'nonsense', pharma leaders claim. The Telegraph. Retrieved from (https://www.telegraph.co.uk/global-health/science-and-disease/patent-poolpotential-covid-19-products-nonsense-pharma-leaders/)

Nhamo, Godwell, David Chikodzi, Hlengiwe Precious Kunene, and Nthivhiseni Mashula. 2021. "COVID-19 Vaccines and Treatments Nationalism: Challenges for Low-Income Countries and the Attainment of the SDGs." Global Public Health 16(3):319-39. doi: 10.1080/17441692.2020.1860249. 
Novella, Steaven. 2010. "Demonizing 'Big Pharma."' Science-Based Medicine: Exploring Issues and Controversies in Science and Medicine. Retrieved April 14, 2021 (https://sciencebasedmedicine.org/demonizing-big-pharma/).

Paton, James, Riley Griffin, and Cynthia Koons. 2020. "U.S. Likely to Get Sanofi Vaccine First If It Succeeds." Bloomberg, May 13.

Phelan, Alexandra L., Mark Eccleston-Turner, Michelle Rourke, Allan Maleche, and Chenguang Wang. 2020. "Legal Agreements: Barriers and Enablers to Global Equitable COVID-19 Vaccine Access.” The Lancet 396(10254):800802. doi: 10.1016/S0140-6736(20)31873-0.

Reeve, Belinda, and Lawrence O. Gostin. 2019. “'Big' Food, Tobacco, and

Alcohol: Reducing Industry Influence on Noncommunicable Disease Prevention Laws and Policies Comment on 'Addressing NCDs: Challenges From Industry Market Promotion and Interferences.'" International Journal of Health Policy and Management 8(7):450-54. doi: 10.15171/ijhpm.2019.30.

Reuters Staff. 2021. "Rich, Developing Nations Wrangle over COVID Vaccine Patents." Reuters, March 11.

Roope, Laurence S. J., John Buckell, Frauke Becker, Paolo Candio, Mara Violato, Jody L. Sindelar, Adrian Barnett, Raymond Duch, and Philip M. Clarke. 2020. "How Should a Safe and Effective COVID-19 Vaccine Be Allocated? Health Economists Need to Be Ready to Take the Baton." PharmacoEconomics - Open 4(4):557-61. doi: 10.1007/s41669-020-002285.

Roser, Max, Hannah Ritchie, Esteban Ortiz-Ospina, and Joe Hasell. 2020. "Coronavirus Pandemic (COVID-19)." Our World in Data.

Rotstein, Fiona. 2011. "Is There an International Intellectual Property System?

Is There an Agreement between States as to What the Objectives of Intellectual Property Laws Should Be?" European Intellectual Property Review 33(1).

Rouw, Anna, Adam Wexler, Jennifer Kates, and Josh Michaud. 2021. "Global COVID-19 Vaccine Access: A Snapshot of Inequality." KFF. Retrieved April 4, 2021 (https://www.kff.org/policy-watch/global-covid-19-vaccineaccess-snapshot-of-inequality/).

Sellin, Jennifer Anna. 2015. "Does One Size Fit All? Patents, the Right to Health and Access to Medicines." Netherlands International Law Review 62(3):445-73. doi: 10.1007/s40802-015-0047-5.

Shiffrin, Seana Valentine. 2009. "The Incentives Argument for Intellectual Property Protection Symposium - The Rule of Law in the Information Age: 
Reconciling Private Rights and Public Interest." Journal of Law, Philosophy and Culture 4:49-58.

Silverman, ED. 2020. "Pharma CEOs Push Back on WHO Patent Pool for Covid-19 Products." STAT. Retrieved September 20, 2020 (https://www.statnews.com/pharmalot/2020/05/28/who-voluntary-poolpatents-pfizer/).

Stiglitz, J. E., Jayadev, A., \& Prabhala, A. (2020, April 23). Patents vs. The Pandemic. Project Syndicate. Retrieved May 22, 2021 (https://www.projectsyndicate.org/commentary/covid19-drugs-and-vaccine-demand-patentreform-by-joseph-e-stiglitz-et-al-2020-04)

Story, Alen. 2020. "A Patented Covid-19 Vaccine Could Price out Millions." Green World. Retrieved September 25, 2020 (https://greenworld.org.uk/article/patented-covid-19-vaccine-could-priceout-millions).

Sunder, Madhavi. 2006. "IP3.” Stanford Law Review 59(2):257-332.

Sunder, Madhavi. 2010. Review of "Intellectual Property and Theories of Justice." SSRN Scholarly Paper. ID 1582703. Rochester, NY: Social Science Research Network.

Sunder, Madhavi. 2012. From Goods to a Good Life: Intellectual Property and Global Justice. Yale University Press.

Trachtman, Joel P. 2011. Fragmentation and Coherence in International Law. SSRN Scholarly Paper. ID 1908862. Rochester, NY: Social Science Research Network.

Ulrich, Lauren. 2015. "Trips and Compulsory Licensing: Increasing Participation in the Medicines Patent Pool in the Wake of an HIV/AIDS Treatment Timebomb Comments." Emory International Law Review 30(1):51-84.

Usher, Ann Danaiya. 2020. "South Africa and India Push for COVID-19 Patents Ban." The Lancet 396(10265):1790-91. doi: 10.1016/S01406736(20)32581-2.

Vanderslott, Samantha, Bernadeta Dadonaite, and Max Roser. 2013. "Vaccination." Our World in Data. Retrieved April 4, 2021 (https://ourworldindata.org/vaccination).

Vaccine Procurement: Tracking COVID-19 Vaccine Purchase across the Globe. (2021, May). Launch and Scale Speedometer. Retrieved May 22, 2021 (https://launchandscalefaster.org/covid-19/vaccineprocurement)

Verbeure, Birgit, Esther van Zimmeren, Gert Matthijs, and Geertrui Van Overwalle. 2006. "Patent Pools and Diagnostic Testing." Trends in Biotechnology 24(3):115-20. doi: 10.1016/j.tibtech.2006.01.002. 
Wibulpolprasert, Suwit, Vichai Chokevivat, Cecilia Oh, and Inthira Yamabhai. 2011. "Government Use Licenses in Thailand: The Power of Evidence, Civil Movement and Political Leadership." Globalization and Health 7(1):32. doi: 10.1186/1744-8603-7-32.

Williams, Sean. 2015. “7 Facts You Probably Don’t Know About Big Pharma.” The Motley Fool. Retrieved April 14, 2021 (https://www.fool.com/investing/value/2015/07/19/7-facts-you-probablydont-know-about-big-pharma.aspx).

Woods, Eric Taylor, Robert Schertzer, Liah Greenfeld, Chris Hughes, and Cynthia Miller-Idriss. 2020. "COVID-19, Nationalism, and the Politics of Crisis: A Scholarly Exchange." Nations and Nationalism 26(4):807-25. doi: https://doi.org/10.1111/nana.12644.

World Health Organization. 2020. Promoting Access to Medical Technologies and Innovation: Intersections between Public Health, Intellectual Property and Trade. World Health Organization.

Wouters, Olivier J., Kenneth C. Shadlen, Maximilian Salcher-Konrad, Andrew J. Pollard, Heidi J. Larson, Yot Teerawattananon, and Mark Jit. 2021. "Challenges in Ensuring Global Access to COVID-19 Vaccines: Production, Affordability, Allocation, and Deployment." The Lancet 397(10278):102334. doi: 10.1016/S0140-6736(21)00306-8.

Young, Margaret A. 2012. Regime Interaction in International Law: Facing Fragmentation. Cambridge, UNITED KINGDOM: Cambridge University Press.

Zakir, Foziyah, Farah Islam, Aamena Jabeen, and Sivakumar Sivagurunathan Moni. 2019. "Vaccine Development: A Historical Perspective."

Zarocostas, John. 2021. "New WTO Leader Faces COVID-19 Challenges." The Lancet 397(10276):782. doi: 10.1016/S0140-6736(21)00507-9.

Zlinkoff, Sergel S. 1943. "Monopoly Versus Competition: Significant Trends in Patent, Anti-Trust, Trade-Mark, and Unfair Competition Suits." The Yale Law Journal 53(3):514-52. 